\title{
Disparities in Quality of Primary Care by Resident and Staff Physicians: Is There a Conflict Between Training and Equity?
}

\author{
Utibe R. Essien, $M D, M P H^{1,2}$, Wei He, MPH ${ }^{3}$, Alaka Ray, MD ${ }^{4,5}$, Yuchiao Chang, PhD ${ }^{3,5}$, \\ Jonathan R. Abraham, MPH', Daniel E. Singer, $\mathrm{MD}^{3,5}$, and Steven J. Atlas, MD, MPH ${ }^{3,5}$
}

'Division of General Internal Medicine, University of Pittsburgh School of Medicine, Pittsburgh, PA, USA; ${ }^{2}$ Center for Health Equity Research and Promotion, VA Pittsburgh Healthcare System, Pittsburgh, PA, USA; ${ }^{3}$ Division of General Internal Medicine, Massachusetts General Hospital, Boston, MA, USA; ${ }^{4}$ Department of Medicine, Massachusetts General Hospital, Boston, MA, USA; ${ }^{5}$ Harvard Medical School, Boston, MA, USA.

BACKGROUND: Outpatient primary care experience is vital to internal medicine resident training but may impact quality and equity of care delivered in practices that include resident physicians. Understanding whether quality differences exist among resident and staff primary care physicians (PCPs) may present an opportunity to address health disparities within academic medical centers.

OBJECTIVE: To determine whether there are differences in the quality of primary care provided by resident PCPs compared to staff PCPs.

DESIGN: A retrospective cohort study with a propensitymatched analysis.

PARTICIPANTS: 143,274 patients, including 10,870 patients managed by resident PCPs, seen in 16 primary care practices affiliated with an academic medical center.

MAIN MEASURES: Guideline-concordant chronic disease management of diabetes (HbAlc, LDL) and coronary artery disease (LDL), preventive breast, cervical, and colorectal cancer screening, and resource utilization measures including emergency department (ED) visits, hospitalizations, high-cost imaging, and patient-reported health experience.

KEY RESULTS: At baseline, there were significant differences in sociodemographic and clinical characteristics between resident and staff physician patients. Resident patients were less likely to achieve chronic disease and preventive cancer screening outcome measures including LDL at goal (adjusted OR [aOR] 0.77 [95\% CI 0.65, 0.92]) for patients with coronary artery disease; HbAlc at goal (aOR 0.73 [95\% CI 0.62, 0.85]) for patients with diabetes; breast (aOR 0.56 [95\% CI 0.49, 0.63]), cervical (aOR 0.66 [95\% CI 0.60, 0.74]), and colorectal (aOR 0.72 [95\% CI 0.65, 0.79] cancer screening. Additionally, resident patients had higher rates of ED visits and hospitalizations but lower rates of high-cost imaging. Resident patients reported lower rates of satisfaction with certain access to care and communication measures. Similar outcomes were noted in propensity-matched sensitivity analyses.

Electronic supplementary material The online version of this article (https://doi.org/10.1007/s11606-019-04960-5) contains supplementary material, which is available to authorized users.

Received June 11, 2018

Revised November 30, 2018

Accepted February 26, 2019

Published online April 8, 2019
CONCLUSION: After controlling for differences in sociodemographic and clinical factors, resident patients were less likely to achieve chronic disease and preventive cancer screening outcomes compared to staff patients. Further efforts to address ambulatory trainee education and primary care quality along with novel approaches to the management of the disproportionately disadvantaged resident patient panels are needed.

KEY WORDS: resident; primary care; quality; racial and ethnic disparities; medical education.

$\mathrm{J}$ Gen Intern Med 34(7):1184-91

DOI: $10.1007 / \mathrm{s} 11606-019-04960-5$

(c) Society of General Internal Medicine 2019

\section{BACKGROUND}

Ambulatory practice and education is a key aspect of training for the nearly 8000 internal medicine (IM) residents across the country. ${ }^{1,2}$ Though most of their residency time is spent on inpatient rotations, IM residents are likely, with the exception of those practicing hospital medicine, to spend the majority of their clinical practice in the outpatient setting, where close to 1 billion patient encounters occur annually. ${ }^{3}$ To date, efforts to measure the quality of care in the outpatient setting have primarily focused on patients seen by post-training staff physicians, although there has been increased interest in assessing the care of patients seen by resident physicians. ${ }^{4-6}$

Prior studies have shown mixed results when comparing patient outcomes of resident and staff primary care physicians (PCPs), with some studies actually finding better outcomes for resident patients. $^{7-11}$ However, as the demands of the health system grow and resident work hour regulations increase, few studies have examined contemporary primary care outcomes of patients cared for by resident PCPs. ${ }^{12,13}$ Additionally, even less is known about the patient experience when receiving primary care from residents compared to staff PCPs. ${ }^{14-16} \mathrm{As}$ resident physicians often care for a larger proportion of outpatients from underserved backgrounds compared with staff physicians, understanding whether differences in quality of care exist among resident and staff PCPs may present an opportunity to improve equity of care within academic health centers. ${ }^{17,} 18$ Identifying areas where quality outcomes of 
resident and staff PCPs differ may also help guide training directors and primary care health system leaders in how best to optimize the outpatient setting for education and high-quality patient care. ${ }^{19-21}$

In this analysis, we sought to assess outcomes of patients seen in the same clinics by resident and staff PCPs at a large academic medical center in the modern medical education era, and to examine whether differences persist after controlling for patient demographic, clinical, and socioeconomic characteristics, along with practice-based features. The objectives of our analysis were to assess whether differences exist between resident and staff physician PCPs for the following outcomes: (1) chronic disease management, specifically related to diabetes mellitus (DM) and coronary artery disease (CAD); (2) preventive cancer screening including breast, cervical, and colorectal; (3) resource utilization; and (4) patient-reported experience of care.

\section{METHODS}

\section{Study Setting and Population}

The cohort for this analysis was derived from the Massachusetts General Hospital (MGH) Practice-Based Research Network $(\mathrm{PBRN})$ and included patients receiving longitudinal primary care at MGH. The PBRN includes 16 primary care clinics where resident and staff physicians provide longitudinal outpatient care, including four community health centers. At MGH, resident physicians are supervised by staff physicians within the same clinical spaces and have access to the same resources as staff physicians including care coordination and allied health professionals. ${ }^{22}$ Patients seen within this network are connected to specific staff physicians using a previously validated algorithm. ${ }^{23}$ Those patients not attributed to a specific staff physician are then connected with a primary care practice. ${ }^{24}$ Among patients seen in a given practice but not connected with a specific staff physician, we worked with: (1) the residency program to embed a resident PCP field within the electronic medical record, (2) practice administrative staff to assign patients to the specific resident PCP who followed them, and (3) information technology staff to reassign residents who completed training with new residents taking over the patient panel.

Inclusion criteria for the cohort included patients seen within one of 16 primary care clinics affiliated with MGH between January 1, 2014, and December 31, 2016, who were linked to a specific resident or staff PCP. Excluded patients were those who were not linked to a specific resident or staff PCP, those who died, or those who left the network. The Institutional Review Board at Partners Healthcare approved this study.

\section{Patient Demographic and Clinical Factors}

Data was obtained from electronic data sources including registration information for patient demographic characteristics and electronic medical records for problem list and billing code diagnoses, appointment information, laboratory and procedure data, and emergency department (ED) and hospital admission data. ${ }^{25}$ Patient-level demographic information included age, gender, self-reported race/ethnicity, spoken language preference, insurance status, educational attainment, and poverty level based on zip code-derived median household income (algorithms for which have been previously described) ${ }^{26}$ Clinical information included the clinic site, patient years in the primary care network, mental illness (including depression), substance use disorder (using billing codes and problem list diagnoses), Charlson Comorbidity Index (an index for medical comorbidity), and Higashi score (a sum of common comorbid conditions). ${ }^{27,28}$

\section{Outcomes}

For all eligible patients in the cohort, we assessed outcomes using data from the calendar year 2016. This included items derived from Healthcare Effectiveness Data and Information Set (HEDIS) performance measures based upon their role in evaluating quality of care. ${ }^{29}$ Data were obtained from the Research Patient Data Registry (RPDR), an electronic data repository within the Partners Healthcare System. ${ }^{25}$ Quality of care included outcomes of chronic disease management, specifically for patients with DM and CAD. The algorithms used to identify patients diagnosed with DM and CAD have been previously described. ${ }^{30-32}$ We assessed hemoglobin A1C $(\mathrm{HbAlc})$ and low-density lipoprotein (LDL) testing rates for DM patients, and LDL testing rates for CAD patients within the past year. We also assessed whether $\mathrm{HbAlc}$ and LDL were at clinical goal for each subpopulation. HbA1c at goal $(<9 \%)$ was defined as the most recent $\mathrm{HbAlc}$ value within the past year. For lipid control, LDL at goal $(<100 \mathrm{mg} / \mathrm{dl})$ was defined as the most recent LDL value within the past year, or on a high-intensity statin for patients with CAD or on a high/ moderate-intensity statin for patients with DM. ${ }^{33}$

Further, we examined quality of care measures for preventive cancer screening including breast, cervical, and colorectal cancer, among those who were eligible for testing. Women 50 to 74 years of age were considered up-to-date for routine breast cancer screening if they had a record of having a mammogram in the past 2 years. Women 21 to 64 years of age were considered up-to-date for routine cervical cancer screening if they had a record of having a Papanicolaou test in the past 3 years, or, for women 30 years and older, having an HPV test in the past 5 years. Patients 50 to 75 years of age were considered up-to-date for routine colorectal cancer screening if they had a record of having a colonoscopy in the past 10 years or sigmoidoscopy, barium enema, or computed tomography colonography in the past 5 years. ${ }^{34}$ These data were also obtained using the RPDR. The chronic disease management and preventive cancer screening outcomes selected are quality measures used by the institution's population health management program. ${ }^{35}$

Additionally, resource utilization measures were evaluated, including ED visits, hospital admissions, and percentage of 
high-cost imaging (outpatient CT, MRI, and nuclear medicine tests) per 100 patients. ED visits and hospital admissions were particularly chosen given the well-described association between having a PCP and these outcomes. ${ }^{36,37}$ Lastly, we examined patient-reported healthcare experiences using Consumer Assessment of Healthcare Providers and System (CAHPS) scores to assess timeliness of appointments, care, and information, and provider communication with patients. Patients in the cohort were randomly selected for surveys following outpatient visits as part of routine quality assessment efforts.

\section{Statistical Analysis}

We compared characteristics of patients seen by resident versus staff PCPs using chi-square or $t$ tests as appropriate. To reduce the effect of confounding due to baseline differences between resident and staff patients, we present results from regression models adjusting for sociodemographic and clinical factors including age, gender, race/ethnicity, spopken language, insurance status, education level, area-based median household income, clinic type (health center vs. non-health center), Charlson Comorbidity Index, Higashi score, and patient time in network. We used logistic regression models to evaluate quality of care and patient-reported health experience outcomes, and Poisson regression models for resource utilization outcomes. To take into account the clustering of patients within providers, we used the generalized estimating equations (GEE) approach in all analyses.
As a sensitivity analysis to account for broad sociodemographic and clinical differences and the likely differential distribution of these factors between resident and staff PCP patients, we further compared outcomes from 1:1 propensity score-matched subgroups of resident and staff PCP patients. $^{38}$ The propensity score model included the same sociodemographic and clinical factors listed above. We used a greedy matching algorithm where each resident patient (case) was first matched with a staff PCP patient (control) within five digits of the propensity score. For those that did not match, cases were then matched to controls on four digits of the propensity score. This continued down to a one-digit match. Analyses were performed using SAS version 9.4 (Cary, $\mathrm{NC})$.

\section{RESULTS}

The cohort for this study included 10,870 patients who were followed by resident PCPs and 132,404 patients who were followed by staff PCPs (Table 1). Resident patients were younger and included a smaller proportion of women. Resident patients included a higher proportion of non-white patients and patients whose primary spoken language was not English. A higher proportion of resident patients were not insured or were covered by Medicaid, were living in poverty, and had not completed a high school education. Resident patients also had a shorter time in network than staff patients. Resident patients were more likely to have DM and CAD as

Table 1 Demographic Characteristics of Patients

\begin{tabular}{|c|c|c|c|}
\hline & \multirow{2}{*}{$\frac{\text { Staff PCP }}{(N=132,404)}$} & \multirow{2}{*}{$\frac{\text { Resident PCP }}{(N=\mathbf{1 0 , 8 7 0})}$} & \multirow[t]{2}{*}{$p$ value } \\
\hline & & & \\
\hline Age (mean) & 52.9 & 48.2 & $<0.01$ \\
\hline Female $(\%)$ & 58.6 & 48.7 & $<0.01$ \\
\hline Race/ethnicity (\%) & & & $<0.01$ \\
\hline White & 78.4 & 60.6 & \\
\hline African American & 5.5 & 12.5 & \\
\hline Hispanic & 6.1 & 11.7 & \\
\hline Asian & 6.5 & 7.4 & \\
\hline Other & 2.2 & 6.1 & \\
\hline Primary language English (\%) & 91.7 & 80.3 & $<0.01$ \\
\hline Insurance $(\%)$ & & & $<0.01$ \\
\hline Commercial & 71.0 & 62.1 & \\
\hline Medicare & 21.6 & 19.3 & \\
\hline Medicaid & 5.5 & 15.1 & \\
\hline Un- or self-insured & 2.0 & 3.5 & \\
\hline Living in poverty $(\%)^{*}$ & 10.3 & 19.2 & $<0.01$ \\
\hline Education $(\%)$ & & & $<0.01$ \\
\hline Under HS diploma & 12.3 & 18.9 & \\
\hline High school/GED & 20.6 & 32.3 & \\
\hline College/postgrad & 63.1 & 42.8 & \\
\hline Receiving care in health center $(\%)$ & 31.9 & 28.2 & $<0.01$ \\
\hline Patient time in network (mean years) & 8.6 & 6.3 & $<0.01$ \\
\hline \multicolumn{4}{|l|}{ Comorbidity $(\%)$} \\
\hline Depression & 12.7 & 15.1 & $<0.01$ \\
\hline Substance use disorder & 2.8 & 7.6 & $<0.01$ \\
\hline Coronary artery disease & 6.5 & 8.6 & $<0.01$ \\
\hline Diabetes mellitus & 10.1 & 15.2 & $<0.01$ \\
\hline Charlson score (mean) & 1.9 & 2.0 & $<0.01$ \\
\hline Higashi score (mean) & 1.1 & 1.2 & $<0.01$ \\
\hline
\end{tabular}

*\% living in poverty missing $7.2 \%$ staff $P C P$ and $8.8 \%$ resident $P C P$ data 
Table 2 Quality of Care Outcomes Between Staff and Resident PCP Patients: Chronic Disease Management

\begin{tabular}{|c|c|c|c|c|}
\hline & Staff PCP & Resident PCP & Adjusted odds ratio & $p$ value \\
\hline & $N(\%)$ & $N(\%)$ & $(95 \% \mathrm{CI})$ & \\
\hline CAD-LDL screen & $6680(78.0)$ & $569(60.6)$ & $0.36(0.31,0.43)$ & $<0.01$ \\
\hline CAD-LDL at goal & 6239 (72.9) & $649(69.1)$ & $0.77(0.65,0.92)$ & $<0.01$ \\
\hline DM-HbA1c testing & $8548(64.1)$ & 867 (52.6) & $0.58(0.51,0.66)$ & $<0.01$ \\
\hline DM-HbA1c $<9 \%$ & $10,471(78.5)$ & $1188(72.1)$ & $0.73(0.62,0.85)$ & $<0.01$ \\
\hline DM-LDL screen & $10,554(79.1)$ & $1046(63.5)$ & $0.44(0.38,0.51)$ & $<0.01$ \\
\hline DM-LDL at goal & $10,023(75.1)$ & $1189(72.2)$ & $0.93(0.79,1.08)$ & 0.32 \\
\hline
\end{tabular}

CAD coronary artery disease, LDL low-density lipoprotein, DM diabetes mellitus, HbAlc hemoglobin Alc

well as depression and substance use disorder. Resident patients also had more comorbid conditions as assessed by the Charlson and Higashi scores. These sociodemographic and clinical differences were not observed in the propensity score-matched sample cohorts of 10,784 resident and staff PCP patients (online Appendix Table 1).

\section{Chronic Disease and Preventive Cancer Screening Quality Measures}

Within the cohort, fewer resident patients with CAD had an LDL screening test performed in the past year, and when they did, fewer had an LDL at goal (adjusted OR [aOR] 0.77 [95\% CI $0.65,0.92]$ ) (Table 2). Similarly, a smaller proportion of resident patients with $\mathrm{DM}$ had an $\mathrm{HbA1c}$ test performed within the past year and when tested fewer had an $\mathrm{HbAlc}$ at goal (aOR 0.73 [95\% CI 0.62, 0.85]). A smaller proportion of resident patients with diabetes had an LDL screening test performed and of those tested there was no significant difference in those who had their lipids at goal (aOR 0.93 [95\% CI $0.79,1.08]$ ). When examining preventive cancer screening, eligible resident patients were less likely to have completed breast (aOR 0.56 [95\% CI 0.49, 0.63]), cervical (aOR 0.66 [95\% CI 0.60, 0.74]), or colorectal (aOR 0.72 [95\% CI 0.65, 0.79 ] cancer screening tests (Table 3 ). Similar results were observed in the propensity score-matched sample cohorts (online Appendix Tables 2a and 2b).

\section{Resource Utilization}

When comparing resource utilization between groups, resident physician patients had a higher mean rate of ED visits and hospital admissions, per 100 patients (adjusted rate ratio, ARR 1.53 [95\% CI 1.42, 1.66] and 1.81 [95\% CI 1.65, 1.99]) respectively (Table 4). In contrast, resident patients had a lower rate of outpatient high-cost imaging, per 100 patients,
ARR 0.46 (95\% CI $0.40,0.52)$ compared to staff patients. Similar findings were observed in the propensity scorematched sample cohorts (online Appendix Table 3).

\section{Patient-Reported Health Experience}

When assessing patient-reported health experience scores, we found that resident patients reported less satisfaction with obtaining an appointment for urgent and routine care; on the other hand, we found no difference between resident and staff PCP patients in timeliness of receiving answers to phone questions (Table 5). The majority of patients felt their physicians explained things clearly and showed respect, although staff physician scored marginally higher on these features of communication (Table 5). Given the differential response rate to the survey questions, a propensity score-matched cohort was not examined for patient-reported health experience.

\section{DISCUSSION}

Primary care is a key point of entry to the health care system and, as the setting where the majority of patients receive their care, it remains crucial to improving the overall health of a society. ${ }^{39,}{ }^{40}$ Assessing quality of care is integral for highly functioning primary care practice networks. ${ }^{41}$ For primary care practices that include resident physicians as part of IM training programs, this has led to increased interest in evaluating the care of patients seen by resident physicians. This is particularly important given primary care training opportunities are fraught with challenges, including trainee scheduling and supervision, which may impact the quality of care for patients seen by resident physicians. ${ }^{42}$

In this study, we examined the association between provider type (resident vs. staff PCP) and quality of primary care outcomes, resource utilization, and patient-reported experience of

Table 3 Quality of Care Outcomes Between Staff and Resident PCP Patients: Preventive Cancer Screening

\begin{tabular}{|c|c|c|c|c|}
\hline & Staff PCP & Resident PCP & Adjusted odds ratio & $p$ value \\
\hline & $N(\%)$ & $N(\%)$ & $(95 \%$ CI $)$ & \\
\hline Breast cancer screening & $36,766(82.1)$ & $1561(67.8)$ & $0.56(0.49,0.63)$ & $<0.01$ \\
\hline Cervical cancer screening & $44,377(82.4)$ & $2764(69.7)$ & $0.66(0.60,0.74)$ & $<0.01$ \\
\hline Colorectal cancer screening & $43,238(76.8)$ & $2423(65.3)$ & $0.72(0.65,0.79)$ & $<0.01$ \\
\hline
\end{tabular}


Table 4 Resource Utilization Between Resident and Staff PCP Patients

\begin{tabular}{lllll}
\hline \hline & Staff PCP & Resident PCP & Adjusted rate ratio (95\% CI) & $\boldsymbol{p}$ value \\
\hline ED visits* (per 100 pts) & 11.8 & 26.6 & $1.53(1.42,1.66)$ & $<0.01$ \\
Hospital admissions* (per 100 pts) & 6.4 & 14.6 & $1.81(1.65,1.99)$ & $<0.01$ \\
High-cost imaging* (per 100 pts) & 9.6 & 4.2 & $0.46(0.40,0.52)$ & $<0.01$ \\
\hline
\end{tabular}

*Mean annual rate

ED emergency department

care. First, we found that resident patients were more likely to have demographic and socioeconomic characteristics associated with underserved populations such as living in poverty, English not being one's primary language, and use of Medicaid insurance. Second, after controlling for available clinical and sociodemographic factors, resident patients were less likely to complete chronic disease quality measures, specifically $\mathrm{HbA} 1 \mathrm{c}$ and LDL testing, and have these measures at goal. Third, resident patients were less likely to complete preventive cancer screening, specifically breast, cervical, and colorectal. Fourth, resident patients had higher rates of ED visits and hospital admissions than staff patients. Lastly, patient-reported satisfaction was similar between resident and staff PCP patients, though patients generally rated access and communication more positively when they had a staff PCP.

Similar to prior studies, we have shown that there are major differences in the characteristics of patients seen by resident and staff physicians, though the direction of these differences has varied. ${ }^{43}$ For example, using the National Hospital Ambulatory Medical Care Survey (NHAMCS) data from 1997 to 2004, Zallman and colleagues found that resident patients were more likely to be from underrepresented minority backgrounds and to have Medicaid insurance. Yet resident physicians in this study performed better in various processes of care measures including prescribing angiotensin-converting enzyme inhibitors for patients with congestive heart failure and diuretics for those with hypertension. ${ }^{8}$ While the NHAMCS study examined process of care measures, particularly those reinforced by inpatient training, it did not measure clinical outcomes such as LDL and HbAlc measures, a feature unique to the current analysis. In a separate study of primary care clinics at New York Hospital-Cornell Medical Center, Charlson et al. found that, during a 1-year period, resident patients had higher ambulatory costs than attending physicians, particularly related to radiology costs and consultations. ${ }^{7}$ This study focused on comparing costs associated with high-resource utilization between resident and staff PCP patients and did not examine important chronic disease and preventive screening quality measures evaluated in the current analysis. These prior studies report outcomes from many years ago and may not reflect the current resident education or primary care practice environment. Additionally, neither study examined patient experience of care, a factor distinctive to the present study. In a more recent analysis that evaluated inpatient to outpatient transitions of resident patients compared to staff patients, Doctoroff et al. found that resident patients had lower rates of timely post-discharge follow-up than staff physicians. ${ }^{44}$ However, these data were limited to patients who were recently hospitalized and did not examine preventive care outcomes.

Differences in quality of care outcomes between resident and staff physicians may arise for several reasons. First, variability in clinical skills and the inherently limited experience of residents, particularly in the ambulatory setting, may lead to lower quality of care, including achieving chronic disease management targets and preventive cancer screening tests, among resident patients. $^{45-49}$ Second, the disruption in continuity caused by patient transition of care every 2 to 3 years to another resident provider may impact the management of chronic diseases and preventive care, resulting in delays in testing and adverse patient outcomes. $^{50-53}$ Third, as reflected in this cohort, resident PCPs tend to have patient panels with a higher proportion of medically and socially complex individuals compared to staff PCPs which may result in disparate patient outcomes. ${ }^{54,55}$ Fourth, residency continuity clinic scheduling models have faced challenges in balancing the needs of inpatient and outpatient care, sometimes

Table 5 Patient-Reported Health Experience Between Resident and Staff PCPs

\begin{tabular}{|c|c|c|c|c|}
\hline & $\begin{array}{l}\text { Staff PCP } \\
N(\%)\end{array}$ & $\begin{array}{l}\text { Resident } \\
\operatorname{PCP} N(\%)\end{array}$ & Adjusted odds ratio (95\% CI) & $p$ value \\
\hline \multicolumn{5}{|l|}{ Access } \\
\hline Got appointment for urgent care & 1748 (72.6) & $128(64.3)$ & $0.68(0.50,0.92)$ & 0.02 \\
\hline Got appointment for routine care & $2958(70.5)$ & $232(61.9)$ & $0.68(0.55,0.85)$ & $<0.01$ \\
\hline $\begin{array}{l}\text { Got answer to phone questions during } \\
\text { regular office hours on the same day }\end{array}$ & $1564(63.7)$ & $119(58.9)$ & $0.82(0.61,1.09)$ & 0.20 \\
\hline \multicolumn{5}{|l|}{ Communication } \\
\hline Provider explained things clearly & $5083(89.8)$ & $440(85.3)$ & $0.66(0.51,0.85)$ & $<0.01$ \\
\hline Provider listened carefully & $5155(90.8)$ & $454(88.7)$ & $0.80(0.60,1.06)$ & 0.13 \\
\hline Provider showed respect & $5308(93.7)$ & $462(90.1)$ & $0.61(0.45,0.83)$ & $<0.01$ \\
\hline Provider spent enough time & $4913(86.8)$ & $432(85.0)$ & $0.87(0.67,1.11)$ & 0.25 \\
\hline
\end{tabular}


resulting in significant gaps in residents' presence in clinic, which can impact continuity with patients as well as completion of patient care tasks. ${ }^{56}$ In addition, resident PCPs may not utilize resources available within the practice, such as allied health professionals, electronic medical record reporting, and population health coordinators, as effectively as their staff counterparts. ${ }^{57}$ While each resident PCP evaluated in this analysis had access to these resources, we did not examine whether differential utilization of team-based care exists between resident and staff physicians. Lastly, resident physician patients were followed for fewer years within the primary care practice compared to staff patients; though we controlled for this factor, it may still be a marker of limited patient engagement in primary care and a potential factor affecting the outcomes observed in this study and in resident ambulatory care overall. ${ }^{58}$

The findings of this study have important implications for the quality of primary care, particularly for underserved populations. As we observed, resident physicians care for a predominantly underserved patient population. Thus, the quality of care that they offer plays an important role in the health-related disparities that are present in lower income, racial/ethnic minority patients, including chronic disease management and preventive care outcomes. ${ }^{59}$ There is a need for closer attention to how patients from various sociodemographic backgrounds are introduced into the primary care system, and how underserved patients are managed by a constantly changing cadre of resident physicians. Striking the appropriate balance is vital as the medical system strives to train physicians while providing high-quality and equitable care to all patients.

\section{LIMITATIONS}

This was one of the larger studies examining resident and staff PCP quality of care, and included care provided at 16 different primary care practices; however, being a single-institution study may limit the generalizability of our findings. In addition, since it is an observational study, we cannot exclude the possibility that residual and/or unmeasured confounding exists, even after performing propensity score matching, especially given the large differences observed. While resident PCPs practice in the same clinical settings as staff $\mathrm{PCPs}$, there may be differences in the utilization of available resources that would limit the health care system equivalence between the two provider types. Additionally, we were unable to isolate the effect of resident supervision in the present analysis. Since clinical supervision has been found to be associated with improved patient- and education-related outcomes, it is possible the differences observed in this study would be even greater without resident supervision. ${ }^{60}$ Most of the data were obtained from a clinical research database which has been previously validated, yet some unavailable patient-level characteristics, such as employment status, health literacy, and social support, may have limited our ability to adjust for all the factors that affect an individual's clinical and socioeconomic status. We did not examine provider-specific factors such as age, gender, race, or time in practice, some of which have been shown to impact patient-perceived quality and use of health care ${ }^{61}$ Lastly, the available data did not allow us to capture differences between resident and staff PCPs in ordering rates for screening tests. While it is possible that resident patients were less likely to complete a screening test even though it was ordered, it is unlikely this would explain the large differences observed in study outcomes.

\section{CONCLUSION}

In a large primary care network affiliated with an academic medical center, we found that patients of resident physicians were less likely to achieve chronic disease quality of care and preventive cancer screening measures, had higher resource utilization including ED visits and hospital admission, and lower patient-reported satisfaction with care on certain measures. Our results highlight a potential conflict between the goals of postgraduate medical training and the quality of care provided to patients of trainees, particularly among underserved populations. Novel approaches are needed to address residency ambulatory medical education, a central issue to improving overall quality and equity of primary care.

Acknowledgements: The authors would like to thank Ethan Lennox, MA, for his assistance in the preparation of this manuscript.

Corresponding Author: Utibe R. Essien, MD, MPH; Division of General Internal Medicine University of Pittsburgh School of Medicine, 3609 Forbes Avenue, Suite 2, Pittsburgh, PA, USA (e-mail: uessien@pitt.edu).

Funders Utibe R. Essien's role in the research reported in this publication was supported by the National Research Service award grant T32 HP10251.

\section{Compliance with Ethical Standards:}

The Institutional Review Board at Partners Healthcare approved this study.

Conflict of Interest: The authors declare that they do not have a conflict of interest.

Prior Presentations: A version of the study was presented as a poster at the Society of General Internal Medicine Annual Meeting on April 21, 2017.

\section{REFERENCES}

1. American College of Physicians. Internal medicine residency programs continue to grow but policies needed to ensure patient access to general internists. https://www.acponline.org/acp-newsroom/internal-medicine-residency-programs-continue-to-grow-but-policies-needed-to-ensure-patient-access. Published 2018. Accessed January 27, 2019.

2. National Resident Matching Program. Thousands of Resident Physician Applicants Celebrate NRMP Match Results. http://www.nrmp.org/pressrelease-thousands-resident-physician-applicants-celebrate-nrmpmatch-results/. Published 2018. Accessed January 27, 2019. 
3. Centers for Disease Control and Prevention (CDC). Ambulatory Care Use and Physician office visits. https://www.cdc.gov/nchs/fastats/physician-visits.htm. Published 2017. Accessed January 27, 2019.

4. Nadkarni M, Reddy S, Bates CK, Fosburgh B, Babbott S, Holmboe E. Ambulatory-based education in internal medicine: Current organization and implications for transformation. Results of a national survey of resident continuity clinic directors. J Gen Intern Med. 2011;26(1):16-20. https://doi.org/10.1007/s11606-010-1437-3

5. Levine DM, Linder JA, Landon BE. The quality of outpatient care delivered to adults in the United States, 2002 to 2013. JAMA Intern Med. 2016. https://doi.org/10.1001/jamainternmed.2016.6217

6. McGlynn Elizabeth A.; Asch Steven M.; Adams John; Keesey Joan; Hicks J; , Kerr EA. The Quality of Health Care Delivered to Adults in the United States. N Engl J Med. 2003;348:2635-2645.

7. Charlson ME, Karnik J, Wong M, McCulloch CE, Hollenberg JP. Does experience matter? A comparison of the practice of attendings and residents. J Gen Intern Med. 2005;20(6):497-503. https://doi.org/10. 1111/j.1525-1497.2005.0085.x

8. Zallman L, Ma J, Xiao L, Lasser KE. Quality of US primary care delivered by resident and staff physicians. J Gen Intern Med. 2010;25(11):1193-1197. https://doi.org/10.1007/s11606-010-1456-0

9. Angstman KB, Garrison GM, Rohrer JE, Dupras DM, O'Grady JS Retail clinic visits: Are resident paneled patients more likely to make multiple visits? Fam Med. 2012;44(4):235-239.

10. Yancy WS, Macpherson DS, Hanusa BH, et al. Patient satisfaction in resident and attending ambulatory care clinics. $J$ Gen Intern Med. 2001;16(11):755-762. https://doi.org/10.1046/j.1525-1497.2001. 91005.x

11. Nguyen DL, Dejesus RS, Wieland ML. Missed appointments in resident continuity clinic: patient characteristics and health care outcomes. $J$ Grad Med Educ. 2011;3(3):350-355. https://doi.org/10.4300/JGME-D10-00199.1

12. Colbert JA. Experiments in Continuity - Rethinking Residency Training in Ambulatory Care. N Engl J Med. 2013;369(6):504-505. https://doi. org/10.1056/NEJMp1301604

13. Brooks JV, Singer SJ, Rosenthal M, Chien AT, Peters AS. Feeling inadequate: Residents' stress and learning at primary care clinics in the United States. Med Teach. 2017:1-8. https://doi.org/10.1080/ 0142159X.2017.1413236

14. Stewart EA, Marzio DH-D, Guggenheim DE, Gotto J, Veloski JJ, Kane GC. Resident scores on a patient satisfaction survey: evidence for maintenance of communication skills throughout residency. J Grad Med Educ. 2011. https://doi.org/10.4300/JGME-D-11-00047.1

15. Francis MD, Warm E, Julian KA, et al. Determinants of Patient Satisfaction in Internal Medicine Resident Continuity Clinics: Findings of the Educational Innovations Project Ambulatory Collaborative. J Grad Med Educ. 2014. https://doi.org/10.4300/JGME-D-13-00159.1

16. Fan VS, Burman M, McDonell MB, Fihn SD. Continuity of care and other determinants of patient satisfaction with primary care. J Gen Intern Med. 2005. https://doi.org/10.1111/j.1525-1497.2005.40135.x

17. Egbert LD, Rothman IL. Relation between the race and economic status of patients and who performs their surgery. N Engl J Med. 1977;297(2):9091. https://doi.org/10.1056/NEJM197707142970205

18. Fiscella K, Sanders MR. Racial and Ethnic Disparities in the Quality of Health Care. Annu Rev Public Heal. 2016;37:375-394. https://doi.org/ 10.1146/annurev-publhealth-032315-021439

19. Sessums LL, Conway PH. Saving Primary Care. JAMA Intern Med. 2017;177(11):1560-1562.

20. Regenstein M, Nocella K, Jewers MM, Mullan F. The Cost of Residency Training in Teaching Health Centers. $N$ Engl $J$ Med. 2016. https://doi. org/10.1056/NEJMp1607866

21. Ayanian JZ, Hamel MB. Transforming Primary Care - We Get What We Pay For. N Engl J Med. 2016. https://doi.org/10.1056/NEJMe1603778

22. Ray A, Jones $\mathbf{D}$, Palamara $\mathbf{K}$, Overland $\mathbf{M}$, Steinberg KP. Improving Ambulatory Training in Internal Medicine: X + Y (or Why Not?). J Gen Intern Med. 2016. https://doi.org/10.1007/s11606-016-3808-x

23. Atlas SJ, Chang Y, Lasko TA, Chueh HC, Grant RW, Barry MJ. Is this "my" patient? Development and validation of a predictive model to link patients to primary care providers. J Gen Intern Med. 2006;21(9):973978. https://doi.org/10.1007/BF02743147

24. Atlas SJ, Grant RW, Ferris TG, Chang Y, Barry MJ. Patient-physician connectedness and quality of primary care. Ann Intern Med. 2009;150(5):325-335. doi:150/5/325 [pii]

25. Murphy SN, Chueh HC. A security architecture for query tools used to access large biomedical databases. Proc AMIA Symp. 2002:552-556. doi: D020002391 [pii]
26. Berkowitz SA, Traore CY, Singer DE, Atlas SJ. Evaluating area-based socioeconomic status indicators for monitoring disparities within health care systems: results from a primary care network. Health Serv Res. 2015;50(2):398-417. https://doi.org/10.1111/1475-6773.12229

27. Charlson ME, Pompei P, Ales KL, MacKenzie CR. A new method of classifying prognostic comorbidity in longitudinal studies: development and validation. J Chronic Dis. 1987;40(5):373-383. http://www.ncbi.nlm. nih.gov/pubmed/3558716. Accessed January 27, 2019.

28. Higashi T, Wenger NS, Adams $\mathbf{J L}$, et al. Relationship between Number of Medical Conditions and Quality of Care. $N$ Engl $J$ Med. 2007;356(24):2496-2504. https://doi.org/10.1056/NEJMsa066253

29. National Committee for Quality Assurance. HEDIS Measures and Technical Resources. https://www.ncqa.org/hedis/measures/. Published 2018. Accessed November 16, 2018.

30. Grant RW, Cagliero E, Sullivan CM, et al. A controlled trial of population management: Diabetes mellitus: Putting Evidence into Practice (DMPEP). Diabetes Care. 2004;27(10):2299-2305. https://doi.org/10.2337/ diacare.27.10.2299

31. DeFaria Yeh D, Freeman MW, Meigs JB, Grant RW. Risk factors for coronary artery disease in patients with elevated high-density lipoprotein cholesterol. Am J Cardiol. 2007;99(1):1-4. https://doi.org/10.1016/j. amjcard.2006.07.053

32. Hivert M-F, Grant RW, Shrader P, Meigs JB. Identifying primary care patients at risk for future diabetes and cardiovascular disease using electronic health records. BMC Health Serv Res. 2009;9(1):170. https:// doi.org/10.1186/1472-6963-9-170

33. Stone NJ, Jennifer Robinson C, Chair Alice Lichtenstein VH, et al. Stone NJ, et al. 2013 ACC/AHA Blood Cholesterol Guideline 2013 ACC/ AHA Guideline on the Treatment of Blood Cholesterol to Reduce Atherosclerotic Cardiovascular Risk in Adults EXPERT PANEL MEMBERS ACC/ AHA TASK FORCE MEMBERS Subcommittee on Prevention Guidelines. http://circ.ahajournals.org/content/circulationaha/early/2013/11/11/ 01.cir.0000437738.63853.7a.full.pdf. Accessed January 27, 2019.

34. Recommendations for Primary Care Practice - US Preventive Services Task Force. https://www.uspreventiveservicestaskforce.org/Page/ Name/recommendations. Accessed January 27, 2019.

35. Ashburner JM, Horn DM, O'Keefe SM, et al. Chronic disease outcomes from primary care population health program implementation. Am J Manag Care. 2017;23(12):728-735.

36. Hurley RE, Freund DA, Taylor DE. Emergency room use and primary care case management: Evidence from four medicaid demonstration programs. Am J Public Health. 1989. :https://doi.org/10.2105/AJPH.79.7.843

37. Starfield B. Is primary care essential? Lancet. 1994. https://doi.org/10. 1016/S0140-6736(94)90634-3

38. Stuart EA. Matching Methods for Causal Inference: A Review and a Look Forward. Stat Sci. 2010. https://doi.org/10.1214/09-STS313

39. Bazemore A, Stange KC, Ferrer RL. The paradox of primary care. In: Family Medicine: The Classic Papers. ; 2016. https://doi.org/10.1201/ 9781315365305

40. Barkley S, Starfield B, Shi L, Macinko J. The contribution of primary care to health systems and health. In: Family Medicine: The Classic Papers. ; 2016. https://doi.org/10.1201/9781315365305

41. PPC-Patient-Centered Medical. National Committee for Quality Assurance Website. http://www.ncqa.org/. Accessed January 27, 2019.

42. Keirns CC, Bosk CL. Perspective: The unintended consequences of training residents in dysfunctional outpatient settings. Acad Med. 2008;83(5):498-502. https://doi.org/10.1097/ACM.0b013e31816be3ab

43. Khalid L, Liebschutz JM, Xuan Z, et al. Adherence to Prescription Opioid Monitoring Guidelines among Residents and Attending Physicians in the Primary Care Setting. Pain Med. 2015;16(3):480-487. https://doi. org/10.1111/pme.12602

44. Doctoroff L, McNally D, Vanka A, Nall R, Mukamal KJ. Inpatientoutpatient transitions for patients with resident primary care physicians: Access and readmission. Am J Med. 2014;127(9):886.e15-886.e20. https://doi.org/10.1016/j.amjmed.2014.03.038

45. Jena AB, Sun EC, Romley JA. Mortality Among High-Risk Patients With Acute Myocardial Infarction Admitted to US Teaching-Intensive Hospitals in July: A Retrospective Observational Study. Circulation. 2013;128(25):27542763. https://doi.org/10.1161/CIRCULATIONAHA.113.004074

46. Inaba K, Recinos G, Teixeira PGR, et al. Complications and Death at the Start of the New Academic Year: Is There a July Phenomenon? $J$ Trauma Inj Infect Crit Care. 2010;68(1):19-22. https://doi.org/10.1097/ TA.0b013e3181b88dfe

47. Englesbe MJ, Fan Z, Baser O, Birkmeyer JD. Mortality in Medicare Patients Undergoing Surgery in July in Teaching Hospitals. Ann Surg. 2009;249(6):871-876. https://doi.org/10.1097/SLA.0b013e3181a501bd 
48. Changoor NR, Ortega G, Ekladios M, Zogg CK, Cornwell EE, Haider AH. Racial disparities in surgical outcomes: Does the level of resident surgeon play a role? Surgery. 2015;158(2):547-555. https://doi.org/10. 1016/j.surg.2015.03.046

49. Ferraris VA, Harris JW, Martin JT, Saha SP, Endean ED. Impact of Residents on Surgical Outcomes in High-Complexity Procedures. In Journal of the American College of Surgeons. Vol 222. ; 2016:545-555. https://doi.org/10.1016/j.jamcollsurg.2015.12.056

50. Pincavage AT, Ratner S, Prochaska ML, et al. Outcomes for ResidentIdentified High-Risk Patients and Resident Perspectives of Year-End Continuity Clinic Handoffs. J Gen Intern Med. 2012;27(11):1438-1444. https://doi.org/10.1007/s11606-012-2100-y

51. Caines LC, Brockmeyer DM, Tess A V., Kim H, Kriegel G, Bates CK. The Revolving Door of Resident Continuity Practice: Identifying Gaps in Transitions of Care. J Gen Intern Med. 2011;26(9):995-998. https://doi. org/10.1007/s11606-011-1731-8

52. Young JQ, Wachter RM. Academic Year-End Transfers of Outpatients From Outgoing to Incoming Residents. JAMA. 2009;302(12):1327. https://doi.org/10.1001/jama.2009.1399

53. Pincavage AT, Lee WW, Beiting KJ, Arora VM. What do patients think about year-end resident continuity clinic handoffs? A qualitative study. Gen Intern Med. 2013;28(8):999-1007. https://doi.org/10.1007/s11606013-2395-3

54. Pincavage AT, Ratner S, Prochaska ML, et al. Outcomes for ResidentIdentified High-Risk Patients and Resident Perspectives of Year-End Continuity Clinic Handoffs. J Gen Intern Med. 2012;27(11):1438-1444. https://doi.org/10.1007/s11606-012-2100-y

55. Solomon SR, Gooding HC, Reyes Nieva H, Linder JA. Acute Care Utilization by Patients After Graduation of Their Resident Primary Care
Physicians. J Gen Intern Med. 2015;30(11):1611-1617. https://doi.org/ 10.1007/s11606-015-3305-7

56. Wieland M, Jaeger T, Bundrick J. Resident physician perspectives on outpatient continuity of care. J Grad Med Educ. 2013;4(December):668673. https://doi.org/10.4300/JGME-05-04-40

57. Fernald DH, Deaner N, O'Neill C, Jortberg BT, degruy FV, Dickinson WP. Overcoming early barriers to PCMH practice improvement in family medicine residencies. Fam Med. 43(7):503-509. http://www.ncbi.nlm. nih.gov/pubmed/21761382. Accessed January 27, 2019.

58. Hibbard JH, Greene J. What The Evidence Shows About Patient Activation: Better Health Outcomes And Care Experiences; Fewer Data On Costs. Health Aff. 2013;32(2):207-214. https://doi.org/10.1377/ hlthaff.2012.1061

59. Bauer UE, Briss PA, Goodman RA, Bowman BA. Prevention of chronic disease in the 21st century: elimination of the leading preventable causes of premature death and disability in the USA. Lancet. 2014;384(9937):4552. https://doi.org/10.1016/S0140-6736(14)60648-6

60. Farnan JM, Petty LA, Georgitis E, et al. A systematic review: The effect of clinical supervision on patient and residency education outcomes. Acad Med. 2012. https://doi.org/10.1097/ACM.0b013e31824822cc

61. Saha S, Komaromy M, Koepsell TD, Bindman AB. Patient-physician racial concordance and the perceived quality and use of health care. Arch Intern Med. 1999. https://doi.org/10.1001/archinte.159.9.997

Publisher's Note Springer Nature remains neutral with regard to jurisdictional claims in published maps and institutional affiliations. 